\title{
DESCRIÇÃO DE UMA NOVA ESPÉCIE DE PEIXE ANUAL DO ESTADO DA BAHIA, BRASIL (CYPRINODONTIFORMES, RIVULIDAE)
}

\author{
Carlos Alberto G. da Cruz e Oswaldo Luiz Peixoto ${ }^{1}$
}

\section{ABSTRACT}

Cynolebias leitaoi $n$. sp. is described from Mucuri, State of Bahia. This new species is related to the group having females without omamentation pattern in the body and fins.The most distinctive character observed is the pattern of vertical bars in the flank associated to the presence of small drops in the flank and anal, caudal and dorsal fins, of the males.

\section{INTRODUÇÃO}

Os peixes anuais são assim conhecidos por viverem em coleções temporárias de água e produzirem ovos resistentes à dessecação, que são enterrados durante o ritual de cópula e eclodem, em sua maioria, no próximo periodo chuvoso. Alguns gêneros desses peixes ocorrem no Brasil, dos quais Cynolebias destaca-se por ser o mais abrangente em número de espécies e na distribuição geográfica.

Carvalho \& Cruz (1985) descreveram Cynolebias bokermanni do sudeste baiano, assinalando que se tratava do primeiro registro do gênero para o estado da Bahia e que tinham a nítida impressão de que a inexistência de dados sobre a ocorrência de espécies de Cynolebias, até aquela época, nos estados da Bahia, Sergipe e Alagoas, era fruto da falta de colecionamento naquelas áreas.

Em duas ocasiōes, abril e agosto de 1988, os Professores Oswaldo Luiz Peixoto e Sérgio P. Carvalho e Silva e o Graduando Richard Sachsse, estiveram na região de Mucuri, estado da Bahia, onde colecionaram uma pequena espécie de Cynolebias relacionada ao conjunto de espécies que possuem fêmeas desprovidas de padrão de omamentação no corpo e nas nadadeiras ( $C$. minimus, $C$. aureoguttatus, $C$. nanus, entre outras), a qual pela simples observação do padrão de colorido mostrou tratar-se de espécie inédita.

Na oportunidade, apresentamos a descrição dessa nova espécie de Cynolebias, com isso assinalando a ocorrência de mais uma espécie deste gênero para o estado da Bahia.

O local de coleta (Fig. 1) foi uma poça, em mata alterada por cultivo de cacau, à margem do rio Mucuri. Em época de cheia, ela chegava a atingir cerca de 100 metros de comprimento por 4 metros de largura e profundidade máxima de pouco mais de 1 metro. $O$ fundo mostrava-se argiloso e coberto por uma camada de matéria orgânica em decomposição. A superfície estava densamente coberta por plantas como Pistic stratiotes e Ceratophyllum sp. e possuía, ainda, uma vegetação emergente formada principalmente por Ciperáceas.

1. Professores Adjuntos da Ärea de Zoologia do Departamento de Biologia Animal, Instituto de Biologia da Universidade Federal Rural do Rio de Janeiro, Seropédica, I taguaí, RJ, 23851. Bolsistas do Conselho Nacional de Desenvolvimento Científico e Tecnológico (CNPq). 


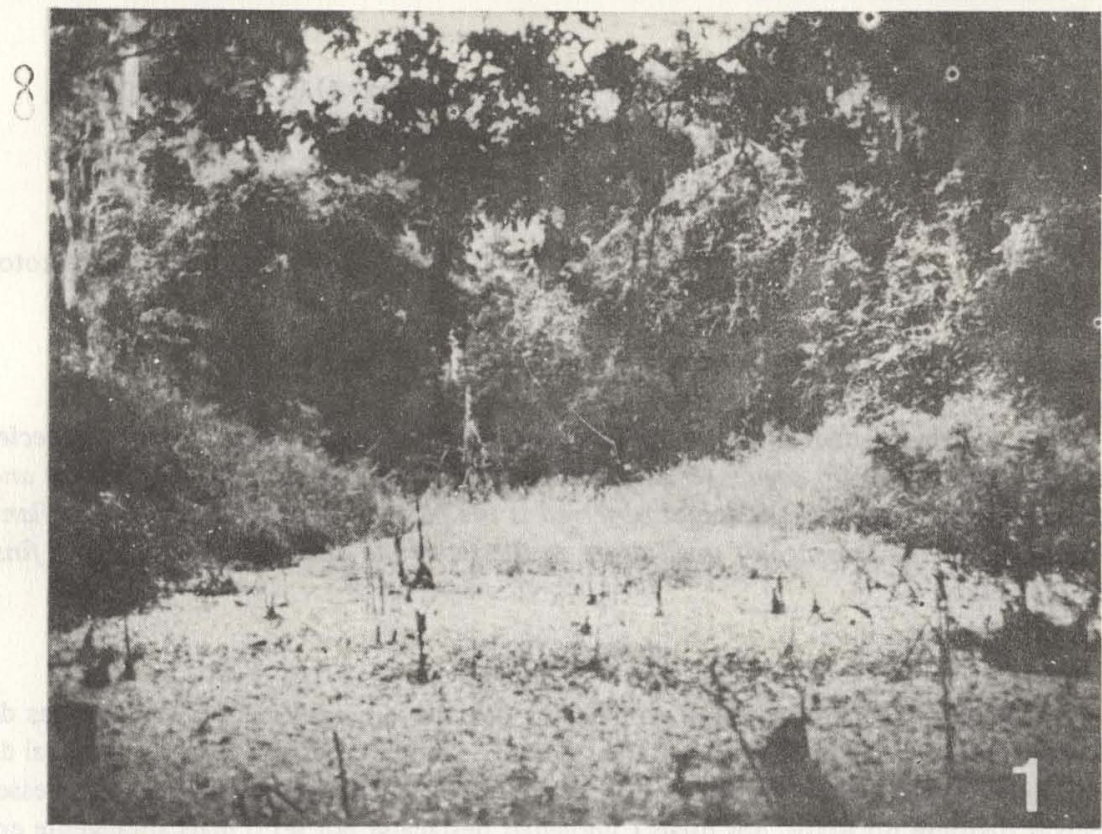

Fig. 1 - Ambiente onde Cynolebias leitooi sp. n. foi colecionada, Mucuri, Estado da Bahia. Foto Richard Sachsse.

O material estudado encontra-se depositado na coleção ictiológica do Museu Nacional do Rio de Janeiro (MN) e na coleçâo Carlos̉ Alberto Gonçalves da Cruz (CAGC), localizada na Universidade Federal Rural do Rio de Janeiro.

Nas mensurações, os números indicados entre parênteses representam valores médios e, nas contagens, os valores modais.

O nome específico atribuido é dedicado à memória do destacado naturalista Professor Antenor Leitão de Carvalho.

\section{Cynolebias leitaoi sp. $\mathrm{n}$.}

(Figs 2-4)

Holótipo: MN 11646, macho adulto, colecionado no período de 18 a 20 de abril de 1988, em Mucuri, Estado da Bahia, por Oswaldo Luiz Peixoto, Sérgio P. Carvalho e Silva e Richard Sachsse.

Parátipos: MN 11647 (2 machos adultos), MN 11648 (5 fêmeas adultas), CAGC 130. $1 / 20$ (5 machos e 15 fêmeas, adultos), colecionados com o holótipo; e CAGC 131. 1/9 ( 7 machos e 2 fêmeas, adultos), colecionados em 16 de agosto de 1988, na mesma localidade, por Oswaldo Luiz Peixoto.

Diagnose: Espécie de porte pequeno, relacionada ao grupo que possui fêmeas desprovidas de padrão de ornamentação no corpo e nas nadadeiras, no qual se diferencia pelo padrão de barras verticais no corpo dos machos (quatro na cabeça e em tomo de dez no flanco) associado à presença de pequenas gotas no flanco e nas nadadeiras anal, caudal e dorsal. 
Vol. 7(4), 1990

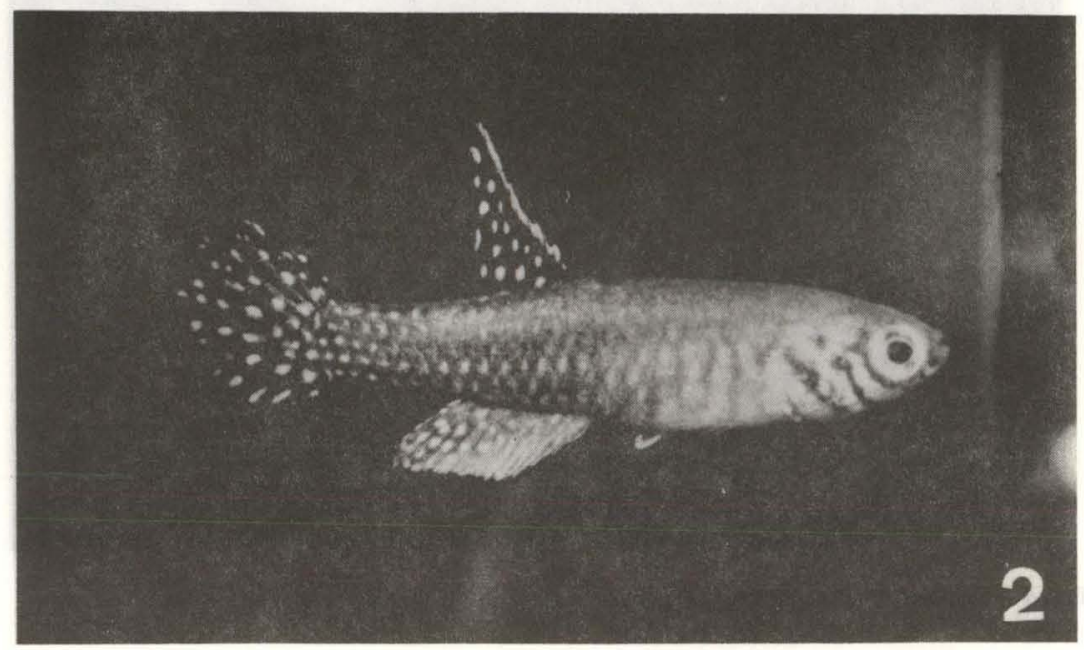

Fig. 2 - Cynolebias leitaoi sp. n., exemplar vivo, macho adulto. Foto Gilberto Campello Brasil.

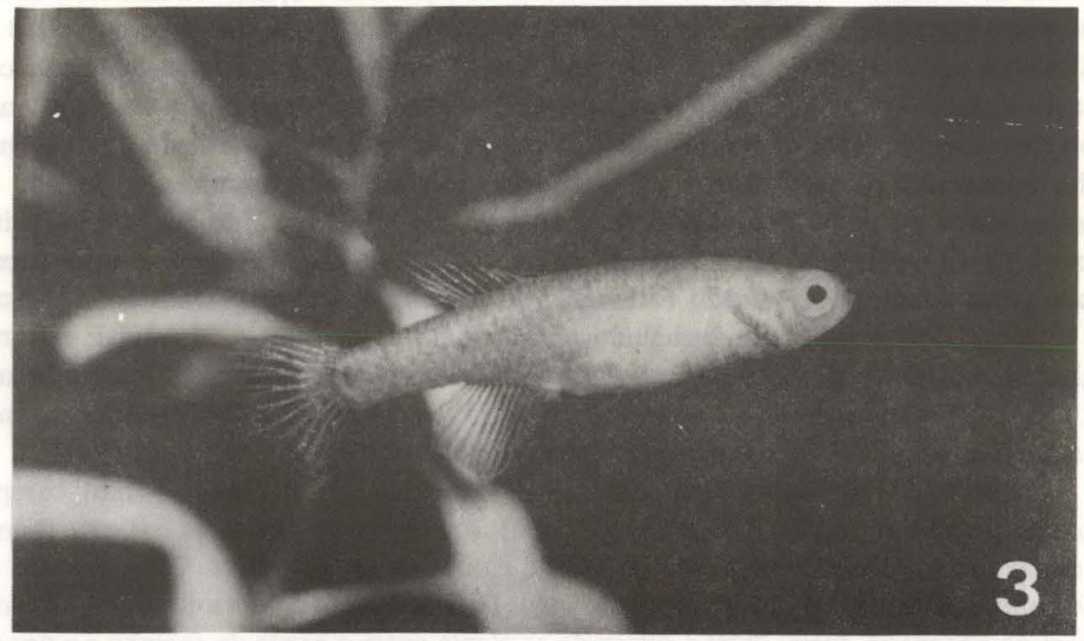

Fig. 3 - Cynolebias leitaoi sp. n., exemplar vivo, fêmeo adulto. Foto Marcelo Notare. 


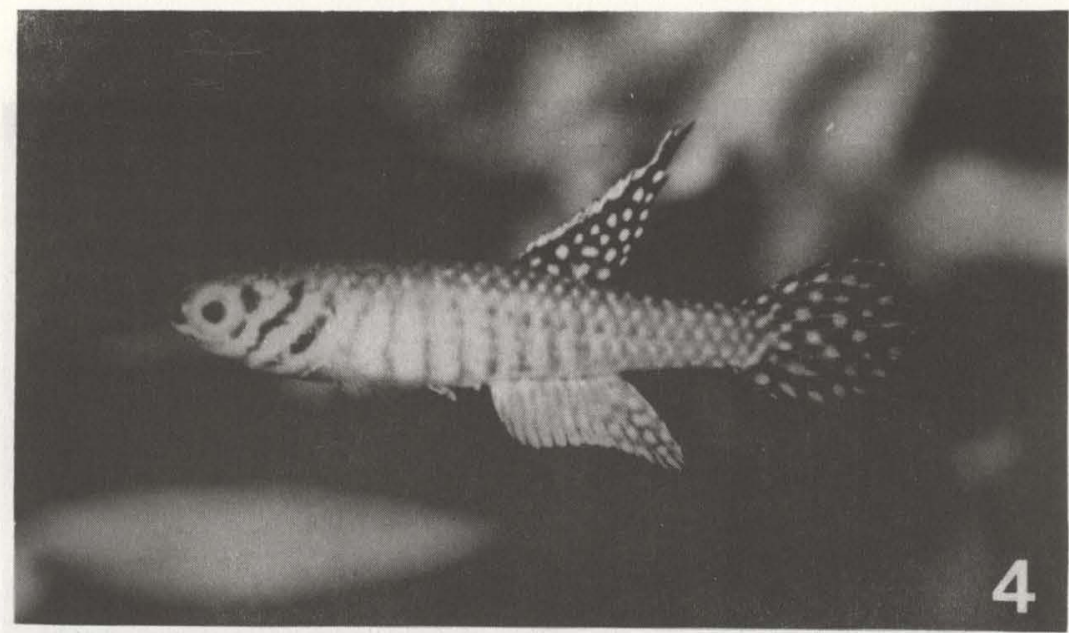

Fig. 4 - Cynolebias leitaoi sp. n., exemplar vivo, macho juvenil. Foto Marcelo Notare.

Descrição dos machos: Comprimento total de 26,0 a $29,0 \mathrm{~mm}$ (27,8 mm); comprimento padrão de 20,5 a $22,0 \mathrm{~mm}(21,2 \mathrm{~mm})$; comprimento da cabeça de 6,0 a $7,0 \mathrm{~mm}$ $(6,5 \mathrm{~mm})$. Diâmetro do olho representando, aproximadamente $1 / 3$ do comprimento da cabeça. Comprimento do focinho igual a metade do diâmetro do olho. Distância entre a ponta do focinho $\mathrm{e}$ a origem da nadadeira dorsal ligeiramente superior à distância entre a ponta do focinho e a origem da nadadeira anal e equivalente a, mais ou menos, o dobro do comprimento da cabeça. Comprimento da base da nadadeira dorsal cerca de $1 / 3$ da distância que a separa da ponta do focinho. Comprimento da base da nadadeira anal cerca da metade da distância que a separa da ponta do focinho. Maior altura do corpo, mais ou menos, equivalente ao comprimento da cabeça e situada numa vertical sobre a origem das nadadeiras pélvicas. Altura do pedúnculo caudal, aproximadamente, metade da maior altura do corpo. Nadadeiras: anal 16 a 17 , caudal 21 a 22 , dorsal 13 a 14 , peitorais 13 a 14 e pélvicas 5 raios. Anal em ponta, atingindo a base da caudal; caudal lanceolada, com filamento destacado formado pelo prolongamento dos ramos do $10^{\circ}$ e e(ou) 11 ? raios; dorsal em ponta, atingindo a metade do comprimento da caudal; peitorais algo lanceoladas e pélvicas pequenas, também lanceoladas. Raios mais longos da anal $13^{\circ}$ e $14^{\circ}$; raios mais longos da dorsal $10^{\circ}$ e e $11^{\circ}$. Linha lateral com 24 escamas; linha transversal com 7 a 8 (8) escamas; pedúnculo caudal contornado por 12 escamas.

Descrição das fêmeas: Comprimento total de 25,0 a $26,0 \mathrm{~mm}(25,5 \mathrm{~mm})$; comprimento padrão de 19,0 a $20,0 \mathrm{~mm}$ (19,5 mm); comprimento da cabeça $6,0 \mathrm{~mm}$. Diâmetro do olho representando cerca de $1 / 3$ do comprimento da cabeça. Comprimento do focinho igual a metade do diâmetro do olho. Distância entre a ponta do focinho e a origem da nadadeira dorsal igual à distância existente entre a ponta do focinho e a origem da nadadeira anal e equivalente ao dobro do comprimento da cabeça. Comprimento da base da nadadeira dorsal aproximadamente $1 / 3$ da distância que a separa da ponta do focinho. Comprimento da base da nadadeira anal ligeiramente superior àquele da dorsal. Maior altura do corpo aproximadamente igual ao comprimento da cabeça e situada 
numa vertical sobre a origem das nadadeiras pélvicas. Altura do pedúnculo caudal cerca da metade da maior altura do corpo. Nadadeiras: anal 15 a 16 (16), caudal 21 a 22, dorsal 12 a 13 (13), peitorais 13 a 14 e pélvicas 5 raios. Dorsal discretamente em ponta; anal, caudal e peitorais arredondadas, e pélvicas lanceoladas. Linha lateral $00 \mathrm{~m} 23$ escamas; linha transversal com 8 escamas; pedúnculo caudal contornado por 12 escamas.

Colorido em vida: Nos machos, a cabeça mostra quatro barras transversais, ligeiramente inclinadas para trás, de cor vermelho vináceo sobre fundo azul esverdeado, localizando-se a primeira sobre o olho e as restantes sobre o opérculo. As barras vermelhas projetam-se ventralmente, sobre fundo branco. A íris é verde-limão. $O$ flanco tem tonalidade avermelhada com pequenas gotas de cor azul esverdeado na metade posterior, enquanto que na metade anterior a tonalidade avermelhada existe apenas em sua porção superior, onde também se observam pequenas gotas idênticas àquelas da metade posterior; já na porção inferior nota-se, apenas, tonalidade esverdeada. Ainda no flanco, destacam-se barras verticais de cor vermelho vináceo que se distribuem desde a margem posterior do opérculo até o limite posterior da base da nadadeira anal, em número em tomo de dez. As barras vermelhas esmaecem da frente para trás, enquanto que as gotas são mais acentuadas na metade posterior do flanco. A nadadeira dorsal é vermelha com pequenas gotas azuis esverdeadas, e com a margem ântero-superior possuindo uma faixa verde. A nadadeira anal exibe na metade basal e na margem posterior, colorido vermetho com pequenas gotas azuis esverdeadas; uma área de tonalidade azulada ocupa a margem anterior e se estreita para trás; na margem distal observa-se uma faixa de cor vermelho vináceo. A nadadeira caudal é vermelha também com pequenas gotas azuis esverdeadas e é contornada por uma fímbria vermelho vináceo. As nadadeiras pélvicas mostram tonalidade azulada e as nadadeiras peitorais são transparentes.

Nas fêmeas, o aspecto geral é pardacento com pontuação escura uniformemente distribuída, exceto no ventre. $O$ dorso é oliváceo e o ventre é branco. $O$ opérculo exibe fracos reflexos esverdeados. A íris tem colorido cúpreo. As nadadeiras são transparentes, exceto as pélvicas que possuem reflexos esverdeados.

Colorido em preservativo (álcool $70^{\circ}$ G.L.): $\mathrm{O}$ aspecto geral, tanto de machos quanto de fêmeas, adquiriu tonalidade que varia do pardo ao marrom.

\section{AGRADECIMENTOS}

Expressamos os nossos agradecimentos ao Professor Sérgio P. Carvalho e Silva e ao Graduando Richard Sachsse pelo auxilio nos trabalhos de campo.

\section{REFERÊNCIAS BIBLIOGRĀFICAS}

CARVALHO, A.L. \& CRUZ, C.A.G., 1985. Um novo Cynolebias do Sudeste Baiano (Pisces, Cyprinodontidae, Rivulinae). Arq. Univ. Fed. Rur. Rio de J., 8 (1-2): 11-15. 